\title{
MicroRNA Expression Profiles in Korean Non-Small Cell Lung Cancer
}

Departments of ${ }^{1}$ Internal Medicine, ${ }^{2}$ Thoracic Surgery, Konyang University Hospital, Daejeon, ${ }^{3}$ Myunggok Research Institute for Medical Science, Konyang University, Daejeon, ${ }^{4}$ Department of Biochemistry, Kyungpook National University School of Medicine, Daegu, ${ }^{5}$ Department of Hospital Pathology, Daejeon St. Mary's Hospital, Daejeon, ${ }^{6}$ Department of Internal Medicine, Kyungpook National University Hospital, Daegu, Korea

Ji Woong Son, M.D. ${ }^{1}$, Young Jin Kim, M.D. ${ }^{2}$, Hyun Min Cho, M.D. ${ }^{2}$, Soo Young Lee, M.S. ${ }^{3}$, Jin Sung Jang, Ph.D. ${ }^{4}$, Jin Eun Choi, M.S. ${ }^{4}$, Jung Uee Lee, M.D. ${ }^{5}$, Min Gyu Kang, M.D. ${ }^{1}$, Yu Mi Lee, M.D. ${ }^{1}$, Sun Jung Kwon, M.D. ${ }^{i}$, Eugene Choi, M.D. ${ }^{1}$, Moon Jun Na, M.D. ${ }^{1}$, Jae Yong Park, M.D. ${ }^{4,6}$

Background: MicroRNAs (miRNAs) play an important role in the regulation of cell proliferation, apoptosis, development and differentiation. Several studies have shown that aberrant expression of miRNAs is involved in cancer development and progression by regulating the expression of proto-oncogenes or tumor suppressor genes. In this study, we investigated miRNA expression profiles in Korean patients with non-small cell lung cancer (NSCLC). Methods: We performed miRNA microarray analysis containing 60 65 bp oligonucleotide probes representing human 318 miRNAs and validated the results of the microarray with Northern blot analysis or quantitative RT-PCR. Next, we examined the correlation between miRNA expression and the target gene transcriptional profile using a human whole-genome-expression microarray.

Results: We showed that 35 miRNAs were expressed differentially in the NSCLCs and corresponding non-malignant lung tissues. We showed that 35 miRNAs were expressed differentially in the NSCLCs and corresponding nonmalignant lung tissues. Thirteen of the 35 differentially expressed miRNAs were newly identified in the present study. Of the 35 miRNAs, 2 (miR-371 and miR-210) were over-expressed in lung cancers, and 33 miRNAs, including miR-145, were under-expressed in lung cancers. miR-99b expression consistently showed a negative correlation with FGFR3 expression.

Conclusion: Albeit a small number of patients were examined, these results suggest that miRNA expression profiles in Korean lung cancers may be somewhat different from the expression profiles reported on lung cancers in Western populations. The findings suggest that miR-99b might be a tumor suppressor through its up-regulation of FGFR3.

Key Words: MicroRNAs; Carcinoma, Non-Small-Cell Lung; Korea

\section{Introduction}

MicroRNAs (miRNAs) are noncoding, single-stranded RNAs of $\sim 22$ nucleotides that repress gene expression

This work was supported by the Korea Research Foundation Grant funded by the Korean Government (MOEHRD, Basic Research Promotion Fund) (KRF-2007-331-E00078).

Address for correspondence: Jae Yong Park, M.D.

Department of Internal Medicine, Kyungpook National University Hospital, 50, Samduk 2-ga, Daegu 700-412, Korea Phone: 82-53-420-5536, Fax: 82-53-426-2046

E-mail: jaeyong@knu.ac.kr

Received: Aug. 14, 2009

Accepted: Sep. 18, 2009 by interacting with messenger RNA (mRNA), either by inhibiting mRNA translation or by inducing mRNA cleavage $^{1-3}$. To date, more than 400 human miRNAs have been identified and up to $30 \%$ of all protein-coding genes are estimated to be regulated by miRNAs ${ }^{2,4,5}$. Although the precise functions of individual miRNAs have not been characterized, biochemical and genetic studies have revealed that miRNAs regulate a variety of biological processes, such as cell proliferation, apoptosis, development and differentiation ${ }^{6-9}$.

miRNA genes are frequently located at chromosomal regions, such as fragile sites, and regions of deletion or 
amplification that are genetically altered in human cancer $^{10,11}$. In addition, it has been reported that some miRNAs are aberrantly expressed or mutated in human cancers, suggesting that they may function as either oncogenes or tumor suppressor genes; depending on the targets they regulate ${ }^{12-14}$. The first evidence of the involvement of miRNAs in cancer came from a study characterizing the 13q14 deletion in chronic lymphocyte leukemia, which revealed that two clustered miRNA genes, miR-15a and miR-16-1, are the target genes of the 13q14 deletion $^{15}$. Subsequently, deregulation of miRNA has been found in various human cancers including lung cancer, such as the down-regulation of let-7 in lung cancer $^{16,17}$, up-regulation of the miR-17-92 cluster in B-cell lymphoma and lung cancer ${ }^{18,19}$, and down-regulation of miR-143 and miR-145 in colorectal cancer ${ }^{20}$.

Using miRNA microarray technology, several groups have revealed miRNA expression profiles in many human cancers ${ }^{21-25}$, and also identified miRNA expression signatures associated with clinical and pathological features as well as disease outcome ${ }^{21-23}$. Although miRNA expression profiles have been studied in lung cancer, the majority of the previous studies were performed on Western populations ${ }^{21,22,26}$. The epidemiological characteristics of lung cancer in East Asian countries are different from those reported from Western countries. For example, lung adenocarcinoma in women, in East Asian countries, frequently develops in never-smokers ${ }^{27,28}$. In addition, several recent studies have shown that mutations in the kinase domain of the epidermal growth factor receptor gene are more frequent in never-smokers, females and East Asian populations, whereas KRAS mutations are more frequent in smokers, males and Western populations ${ }^{29,30}$. These observations, coupled with the differences in the epidemiological characteristics of lung cancer, suggest that the genetic and environmental factors leading to lung cancer in East Asian populations may be different from those of Western populations ${ }^{29,30}$. Therefore, it is possible that miRNA expression profiles in lung cancer among East Asian populations may be different from Western countries. In this study, we investigated the miRNA expression profiles in Korean pa- tients with non-small cell lung cancers (NSCLCs).

\section{Materials and Methods}

\section{Tissue samples}

Tumor and corresponding non-malignant lung tissue specimens were obtained from Korean patients with NSCLC that underwent curative resection at the Konyang University Hospital (Daejeon, Korea). Seven NSCLC cases (4 squamous cell carcinomas [SCCs] and 3 adenocarcinomas [ACs]) were included for miRNA microarray analysis. Four NSCLC cases (3 SCCs and 1 AC) among seven NSCLC case were randomly selected and included for Northern blotting and human whole genome expression microarray analysis. Twenty-three NSCLC cases (19 SCCs and 4 ACs) were included for quantitative RT-PCR (qRT-PCR) (Table 1). None of the patients had received chemotherapy or radiotherapy before surgery. Informed consent was obtained from each patient before surgery. This study was approved by the Bioethics Committee of Konyang University Hospital. All of the tumor and macroscopically normal lung tissue samples were obtained at the time of surgery, and were rapidly frozen in liquid nitrogen and stored at $-80^{\circ} \mathrm{C}$ until analysis. Tissue samples were histologically confirmed by hematoxylin-eosin staining.

Table 1. Characteristics of study populations

\begin{tabular}{lccc}
\hline Characteristics & Microarray & qRT-PCR & p-value \\
\hline Age & $56.57 \pm 13.28$ & $64.69 \pm 9.63$ & $0.085^{\star}$ \\
Gender & & & \\
$\quad$ Male & 5 & 19 & $0.603^{\dagger}$ \\
$\quad$ Female & 2 & 4 & \\
Smoking status & & & \\
$\quad$ Smoker & 5 & 20 & $0.565^{\dagger}$ \\
$\quad$ Never smoker & 2 & 3 & \\
Histology & & & \\
$\quad$ Squamous cell & 4 & 19 & $0.305^{\dagger}$ \\
$\quad$ carcinoma & & & \\
$\quad$ Adenocarcinoma & 3 & 4 & \\
Pathologic stage & & 10 & $0.976^{\dagger}$ \\
$\quad$ Stage I & 3 & 13 & \\
$\quad$ Stage II/ll & 4 & & \\
\hline
\end{tabular}

${ }^{\star}$ Student t-test, ${ }^{\dagger}$ Fisher's exact test. 


\section{2. miRNA extraction}

The total RNA of each sample was extracted using the Trizol reagent (Life Technologies, Carlsbad, CA, USA) according to the instructions of the manufacturer. Low molecular weight (LMW) enriched RNA was isolated from $50 \mu \mathrm{g}$ of total RNA using the mirVana miRNA extraction kit (Ambion Inc., Austin, TX, USA), and quantified using a ND-1000 spectrophotometer (NanoDrop Technologies, Wilmington, DE, USA). RNA quality was evaluated using the Agilent 2100 Bioanalyzer (Agilent Technologies, Palo Alto, CA, USA).

\section{3. miRNA microarray hybridization}

The expression of miRNAs was profiled using a miRNA microarray chip (Genomic Tree Inc., Seoul, Korea) containing 60 65 bp oligonucleotide probes representing human 318 miRNAs. Briefly, $1 \mu \mathrm{g}$ of LMW RNA was labeled using a ULS ${ }^{\mathrm{TM}}$ small RNA labeling kit (Kreatech, Amsterdam, The Netherlands), LMW RNA of an adjacent normal tissue sample was labeled with fluorescent Cy3 and LMW RNA of tumors was labeled with fluorescent Cy5. The fluorescent-labeled LMW RNA was purified using KREApure columns (Kreatech) as per the manufacturer's instructions. The purified target RNA was resuspended in $100 \mu \mathrm{L}$ of hybridization solution containing $3.5 \times \mathrm{SSC}, 0.3 \% \mathrm{SDS}$, and $10 \mu \mathrm{g}$ of ssDNA (Invitrogen). The hybridization mixture was heated at $100^{\circ} \mathrm{C}$ for $2 \sim 3 \mathrm{~min}$ and hybridized onto a miRNA microarray. The array was hybridized at $42^{\circ} \mathrm{C}$ for $16 \mathrm{~h}$ in a humidified hybridization chamber (Genomic Tree Inc.). The hybridized microarray was washed twice with $2 \times \mathrm{SSC} / 0.1 \%$ SDS for $5 \mathrm{~min}, 0.1 \times \mathrm{SSC} / 0.1 \% \mathrm{SDS}$ for $5 \mathrm{~min}$ and $0.1 \times \mathrm{SSC}$ for $2 \mathrm{~min}$. The washed microarray was immediately dried using a microarray centrifuge (Genomic Tree, Inc.).

The hybridization signals were analyzed using a GenePix Pro 6.0 program (Axon Instruments, Foster City, CA, USA). The average fluorescence intensity for each spot was calculated and then the local background was subtracted. All data mining and selection of fold-changed genes were performed using GeneSpringGX 7.3
(Agilent Technologies). Genes were filtered with cut-off values based on the sum of the median of $\geq 1,000$ in each experiment. The averages of the ratios were calculated by dividing the average of the signal channel intensity by the average of the control channel intensity. We considered the results from the Significance Analysis of Microarray 3.0 (SAM) with genes of ratios (Cy5/Cy3) either $\geq 2.0$ or $\leq 0.5$ from $\geq 5$ of 7 tumor samples as significantly different in expression.

\section{Northern blotting and qRT-PCR}

To validate the microarray analysis results, we carried out Northern blot analysis on two (miR-145 and miR210) of the 35 differentially expressed miRNAs using a mirVana miRNA detection kit (Ambion Inc.). Briefly, 3 $\mu \mathrm{g}$ of total RNA was hybridized with 1 pM RNA probe (miR-145, biotin-5'-AAAAGGGAUUCCUGGGAAAACUG GAC-3'; and miR-210, biotin-5'-AAAAUCAGCCGCUGUC ACACGCACAG-3'). The 5S RNA probe (biotin-5'-AAAA UGAUCUCGGAAGCUAA-3') was used to normalize the level of expression. To remove unhybridized RNA, the RNAase A/T1 solution was added, followed by alcohol precipitation. Hybridized RNA was separated on a $15 \%$ denaturing polyacrylamide gel and then electroblotted on a Hybond-Nylon membrane (Amersham Biosciences, Buckinghamshire UK). Detection of hybridized RNA was performed using a non-radioactive LightShift Chemiluminescent kit (Pierce Biotechnol Inc., Rockford, IL, USA). The membrane was UV cross-linked, and the biotin end-labeled hybridized RNA was detected with streptavidin-HRP using a luminal enhancer solution. qRTPCR analysis for miRNAs was performed in duplicate with a TaqMan MicroRNA assay kit (Applied Biosystems, Foster City, CA, USA) according to the instructions of the manufacturer, and 18S RNA was used for normalization.

\section{Human whole genome expression microarray}

For hybridization onto an Agilent Whole Human Genome 4×44 K 60 mer oligonucleotide array (G4112F; Agilent Technologies), $1 \mu \mathrm{g}$ of total RNA was used in the Agilent LIRAK PLUS with the two-color Low RNA 
input Linear Amplification method, according to the manufacturer's instructions. Briefly, the total RNA was reverse transcribed into complimentary DNA (cDNA) using a T7-promotor primer and MMLV reverse transcriptase. The cDNA was transcribed into complimentary RNA (cRNA), during which the cDNA was fluorescently labeled by incorporation of cyanine Cy5-CTP (lung cancer tissue) or Cy3-CTP (normal lung tissue). After purification, using the RNeasy mini kit (Qiagen), the cRNA yield and Cy incorporation efficiency (specific activity) into the cRNA were determined using a NanoDrop Spectrophotometer (NanoDrop Technologies). cRNAs showing a yield $>825 \mathrm{ng}$ and a specific activity of $8 \sim$ $20 \mathrm{pmol} / \mu \mathrm{g} \mathrm{cRNA}$ were selected for further processing. Equal amounts of the exposed and negative control sample were competitively hybridized onto Agilent Whole $4 \times 44 \mathrm{~K}$ human oligonucleotide arrays in a hybridization oven at $60^{\circ} \mathrm{C}$ for $17 \mathrm{~h}$. Slides were washed according to the manufacturer's instructions with washing buffers and finally dipped in Stabilization and Drying

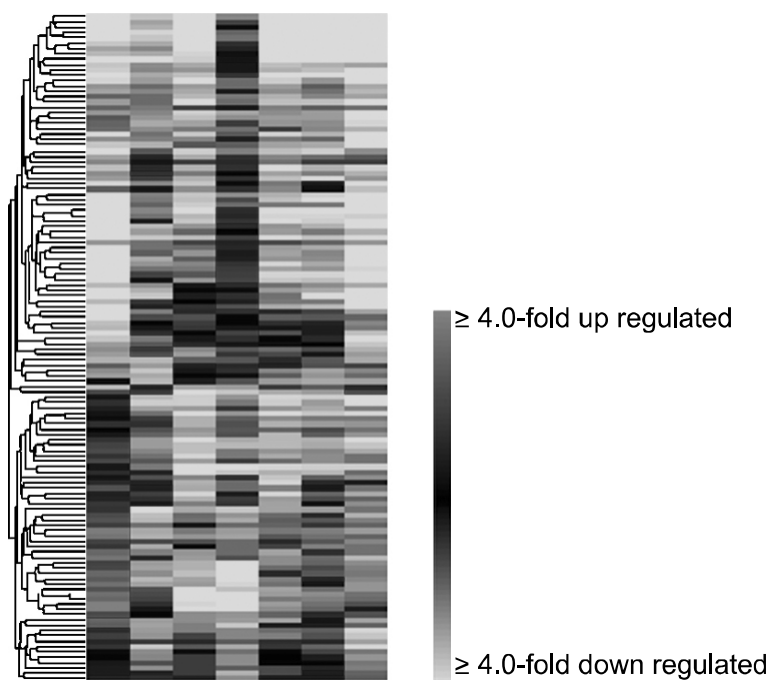

Figure 1. Unsupervised hierarchical clustering of 315 miRNA expression patterns in non-small cell carcinomas and corresponding non-malignant lung tissues. Ratios of miRNA expression are displayed colorimeterically in lung cancers relative to non-malignant lung tissues. The scale bar at the right side represents the relative level of expression of each miRNA. Columns represent array and miRNAs are represented in rows.
Solution (Agilent Technologies) for protection from environmental ozone. The arrays were scanned on an Agilent scanner (G2565BA) and further processed using Agilent Feature Extraction Software (version 9.5.1).

\section{Results}

To generate miRNA expression profiles for NSCLC, we analyzed the expression of 315 human miRNAs using oligonucleotide microarray hybridization chips in 7 pairs of primary lung cancers and corresponding non-malignant lung tissues (Figure 1). We identified 35 miRNA genes that were differentially expressed in the NSCLCs and corresponding non-malignant lung tissues with ratios (Cy5/Cy3) either $\geq 2$ fold or $\leq 0.5$ fold from at least 5 of 7 tumor samples (Table 2). Among the 35 differentially expressed miRNAs, two ( $m i R-371$ and miR-210) were over-expressed in lung cancers, and 33 miRNAs, including miR-145, were under-expressed in lung cancers. Among the 35 differentially expressed miRNAs, 13 of the miRNAs have not been previously reported to be altered in lung cancer; miR-376b, miR-144, miR-520d-5p, miR-520e, miR-520f, miR-23a, miR-296-5p, miR-133a-2, miR-99b, miR-497, miR-425, and miR-338-3p were downregulated, and $m i R-371-3 p$ was up-regulated.

To validate the microarray results, the expression of representative miRNAs were determined using Northern blot analysis (miR-210 and miR-145) and qRT-PCR (miR-210 and miR-29c). Consistent with the results of the microarray analysis, $m i R-210$ was up-regulated in the lung cancers, and miR-145 and miR-29c were down-regulated in the lung cancers (Figure 2).

We predicted tumor-associated target genes of the new 13 miRNAs using 3 public algorithms (MIRAND ${ }^{31}$, TARGETSCAN $^{32}$, and PICTAR ${ }^{33}$ ). The list of putative target genes of 5 miRNAs (miR-144, miR-23a, miR-99b, miR-133a-2, and miR-296-5p), which were predicted by at least 2 of the 3 programs, are shown in Table 3. We next examined the correlation between miRNA expression and target gene transcriptional profiles. Of the 5 miRNAs, miR-99b expression consistently showed a negative correlation with fibroblast growth factor re- 
Tuberculosis and Respiratory Diseases Vol. 67. No. 5, Nov. 2009

Table 2. MiRNAs differentially expressed between lung cancers and their corresponding normal lung tissues

\begin{tabular}{|c|c|c|c|c|c|}
\hline miRNA & Location & Type & Fold & q-value & Results from previous studies \\
\hline hsa-mir-145 & $5 q 32$ & Down & 0.19 & 0 & Down \\
\hline hsa-mir-181a & $1 \mathrm{q} 31.3$ & Down & 0.41 & 0 & Down: 181c-prec \\
\hline hsa-mir-181c & 19p13.12 & Down & 0.37 & 0 & Down: 181c-prec \\
\hline hsa-mir-30a-3p & $6 q 13$ & Down & 0.37 & 0 & Down \\
\hline hsa-mir-30a-5p & $6 q 13$ & Down & 0.46 & 0 & Down $^{\dagger}:$ 30a-3p \\
\hline hsa-mir-30c & $6 q 13$ & Down & 0.34 & 0 & Down: 30a-3p \\
\hline hsa-mir-30d & $8 q 24.22$ & Down & 0.31 & 0 & Down $^{\dagger}: 30 a-3 p$ \\
\hline hsa-mir-30e-3p & 1p34.2 & Down & 0.23 & 0 & Down: 30a-3p \\
\hline hsa-mir-140-5p & $16 q 22.1$ & Down & 0.31 & 0 & Down \\
\hline hsa-mir-143 & $5 q 32$ & Down & 0.38 & 0 & Down \\
\hline hsa-mir-125b & $11 \mathrm{q} 24.1$ & Down & 0.37 & 0 & Down: $125 a, 125 a-p r e c *$ \\
\hline hsa-mir-99a & $21 \mathrm{q} 21.1$ & Down & 0.34 & 0 & Up: 99b prec ${ }^{\dagger}$ \\
\hline hsa-mir-376b & $14 q 32.2$ & Down & 0.51 & 0 & \\
\hline hsa-mir-126 & $9 q 34.3$ & Down & 0.37 & 0 & Down $^{\dagger}$ \\
\hline hsa-mir-101 & 1 p31.3 & Down & 0.37 & 0 & Down: 101-1 \\
\hline hsa-let-7f & $9 q 22.31$ & Down & 0.46 & 0 & $\begin{array}{l}\text { Down: let-7a-2-pre } \\
\text { Up: let-7a and }-7 g^{\dagger}\end{array}$ \\
\hline hsa-mir-95 & $4 p 16.1$ & Down & 0.48 & 0 & Down \\
\hline hsa-mir-144 & $17 q 11.2$ & Down & 0.27 & 0 & \\
\hline hsa-mir-520d-5p & $19 q 13.43$ & Down & 0.51 & 0 & \\
\hline hsa-mir-520e & $19 q 13.43$ & Down & 0.46 & 0 & \\
\hline hsa-mir-520f & $19 q 13.43$ & Down & 0.37 & 0 & \\
\hline hsa-mir-23a & 19p13.2 & Down & 0.43 & 0 & \\
\hline hsa-mir-296-5p & $20 q 13.32$ & Down & 0.46 & 0 & \\
\hline hsa-mir-133a-2 & $18 q 11.2$ & Down & 0.41 & 0 & \\
\hline hsa-mir142-3p & $17 q 22$ & Down & 0.49 & 0 & Up: $142-\mathrm{as}^{\dagger}$ \\
\hline hsa-mir-9 & $15 q 25.3$ & Down & 0.44 & 0 & Down, Up: $9-1^{\dagger}$ \\
\hline hsa-mir-27a & 19p13.2 & Down & 0.51 & 0 & Down: 27b \\
\hline hsa-mir-29c & $1 q 32.1$ & Down & 0.59 & 0 & Down: mir-29b-2 \\
\hline hsa-mir-99b & $19 q 13.43$ & Down & 0.58 & 0 & \\
\hline hsa-mir-497 & $17 p 13.1$ & Down & 0.51 & 0 & \\
\hline hsa-mir-125a & $19 q 13.43$ & Down & 0.43 & 0 & Down \\
\hline hsa-mir-425 & $3 p 21.31$ & Down & 0.56 & 0 & \\
\hline hsa-mir-338-3p & $17 q 25.3$ & Down & 0.37 & 0 & \\
\hline hsa-mir-371-3p & $19 q 13.43$ & Up & 2.63 & 0.93 & \\
\hline hsa-mir-210 & $11 p 15.5$ & Up & 2.51 & 0.93 & $U p^{*, \dagger}$ \\
\hline
\end{tabular}

${ }^{*}$ Ref. 22, ${ }^{\dagger}$ Ref. 26.

ceptor 3 (FGFR3) expression (Table 3).

\section{Discussion}

We performed miRNA expression profiling using microarray analysis in Korean patients with NSCLC and identified a number of miRNAs that were differentially expressed in NSCLCs. To date, two large studies on miRNA expression profiles in lung cancer have been re- ported $^{22,26}$. In a study of 104 matched pairs of lung cancers and non-cancerous lung tissues, Yanaihara et al ${ }^{22}$ identified a set of 43 differentially expressed miRNAs; 28 were down-regulated and 15 were up-regulated. The majority of the miRNAs detected in the present study were the same miRNAs that were identified by Yanaihara et $\mathrm{al}^{22}$. For example, miR-145, miR-181c, miR-30 family, miR-140, miR-143, miR-125, miR-126, miR-101, miR-95, miR-9, and miR-125a were down-regulated and 

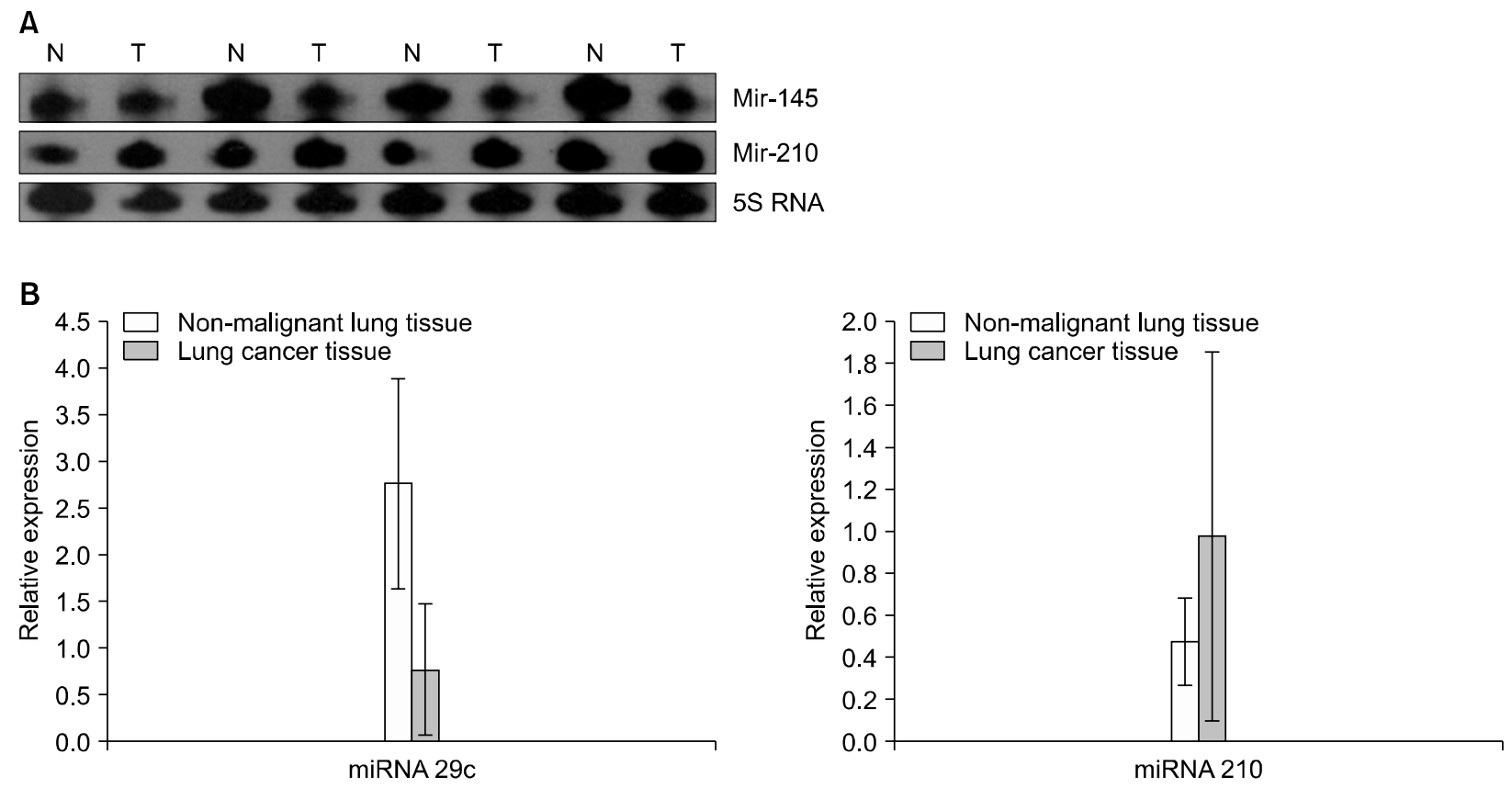

Figure 2. (A) Northern blot analysis for has-miR-145 and has-miR-210 in four paired lung cancers and corresponding non-malignant lung tissues. Has-miR-210 was up-regulated in lung cancers, and has-miR-145 was down-regulated in lung cancers. (B) Quantitative RT-PCR (qRT-PCR) of miRNA expression utilized total RNA isolated from cancer tissues and non-malignant lung tissues. The expression of miRNA was normalized to 18S rRNA expression and was performed in duplicate. Has-miR-29c was down-regulated in lung cancers ( $p=0.0001$, Mann-Whitney's $U$ test), whereas has-miR210 was up-regulated in lung cancer $(p=0.1295)$, although statistically not significant.

miR-210 was up-regulated in both studies (Table 2). In addition, we found that let-7f was down-regulated in lung cancer tissues, which was also consistent with the results of Yanaihara et $\mathrm{al}^{22}$, where let-7a-2 was downregulated in lung cancer. Volinia et $\mathrm{al}^{26}$ also found that lung cancer cells showed distinct miRNA profiles compared to normal cells in a study of 80 lung cancers and 40 normal lung tissues. They reported that 3 miRNAs were down-regulated and 35 miRNAs were over-expressed in lung cancers. When our data were compared with the results of the study reported by Volinia et $\mathrm{al}^{26}$, several miRNAs showed the opposite results of up-regulation or down-regulation. For example, they reported that let-7a, let-7g, miR-142 and miR-9-1 were up-regulated in lung cancers. However, these miRNAs were down-regulated in lung cancers in the present study, as well as in the study reported by Yanaihara et $\mathrm{al}^{22}$. This discrepancy may be due to differences in the methods used in the studies. Volinia et $\mathrm{al}^{26}$ measured the ex- pression of both the pri-miRNAs and the active mature miRNAs simultaneously. Considering that the pri-miRNAs are transient products in miRNA biogenesis, and presumably are rapidly further processed after synthesis ${ }^{34}$, the expression status of the pri-miRNA and the mature miRNA is not necessarily the same. Therefore, the profiles of the combined expression of the pri-miRNAs and the mature miRNAs may be different from the expression of the mature miRNAs ${ }^{24}$.

Racial differences in miRNA expression were reported in uterine leiomyomas. Wang et $\mathrm{al}^{35}$ found that substantial number of miRNAs that are significantly differently regulated between black and white women. Black women had a greater than 2-fold overexpression in miR-23a/b, let-7s, miR-145, miR-197, miR-411, and miR412. In the present study, we found that miR-376b, miR-144, miR-520d-5p, miR-520e, miR-520f, miR-23a, miR-296-5p, miR-133a-2, miR-99b, miR-497, miR-425, and $m i R-338-3 p$ were down-regulated and $m i R-371-3 p$ 
Tuberculosis and Respiratory Diseases Vol. 67. No. 5, Nov. 2009

Table 3. Correlation between microRNA expression profiles and target gene transcriptional profiles in NSCLC

\begin{tabular}{|c|c|c|c|c|c|}
\hline \multirow{2}{*}{ miRNA } & \multirow{2}{*}{ Target gene } & \multicolumn{4}{|c|}{ Target gene transcriptional profiles* } \\
\hline & & Case1 & Case2 & Case3 & Case4 \\
\hline \multirow[t]{8}{*}{ miRNA-144 } & MYBL1 & 0.69 & 0.82 & 0.52 & 0.57 \\
\hline & MAP3K8 & 0.11 & 0.30 & 0.49 & 0.29 \\
\hline & MYCN & 1.20 & 1.09 & 1.24 & 1.32 \\
\hline & MET & 1.12 & 1.25 & 0.95 & 0.41 \\
\hline & ETS1 & 0.36 & 0.79 & 0.38 & 0.51 \\
\hline & TAL1 & 0.74 & 1.23 & 0.93 & 1.42 \\
\hline & HOXA10 & 0.88 & 0.96 & 0.77 & 1.98 \\
\hline & PIM1 & 0.65 & 0.34 & 0.75 & 1.10 \\
\hline \multirow[t]{7}{*}{ miRNA-23a } & ARHGEF5 & 2.11 & 0.77 & 4.15 & 1.56 \\
\hline & CTNNBIP1 & 0.86 & 0.70 & 0.58 & 0.52 \\
\hline & MET & 1.12 & 1.25 & 0.95 & 0.41 \\
\hline & MEIS1 & 0.46 & 1.85 & 0.91 & 0.32 \\
\hline & CCND1 & 1.91 & 2.14 & 0.73 & 0.90 \\
\hline & IRF2 & 0.80 & 1.57 & 1.04 & 0.91 \\
\hline & TEAD1 & 0.56 & 1.17 & 0.47 & 0.44 \\
\hline miRNA-99b & FGFR3 & 2.84 & 1.64 & 9.48 & 6.23 \\
\hline \multirow[t]{8}{*}{ miRNA-133a-2 } & BCL2L2 & 0.98 & 0.77 & 0.72 & 0.66 \\
\hline & EVI1 & 0.30 & 0.90 & 1.41 & 0.87 \\
\hline & FGFR1 & 0.82 & 1.12 & 1.34 & 0.79 \\
\hline & CRK & 1.54 & 1.20 & 1.82 & 1.15 \\
\hline & MLLT3 & 0.46 & 1.88 & 0.64 & 0.61 \\
\hline & YES1 & 1.20 & 0.74 & 1.87 & 1.37 \\
\hline & USP6 & 1.05 & 0.62 & 1.19 & 1.11 \\
\hline & ELF3 & 0.13 & 0.63 & 4.16 & 1.22 \\
\hline miRNA-296-5p & FGFR1 & 0.82 & 1.12 & 1.34 & 0.79 \\
\hline
\end{tabular}

*Ratios of transcription was cy5 (lung cancer tissue)/Cy3 (normal lung tissue) in human whole genome expression microarray.

was up-regulated. To characterize these miRNA, we analyzed their chromosomal location. miR-520d-5p, miR520e, miR-520f, miR-99b, miR-371-3p were located in $19 \mathrm{q} 13.43$.

The results of this study showed that miR-99b was down-regulated in NSCLCs and the expression was negatively correlated with FGFR3 expression. FGFR3 belongs to a family of structurally-related tyrosine kinase receptors (FGFR1 4) involved in many aspects of embryogenesis and tissue homeostasis. These receptors regulate various biological processes, including proliferation, differentiation, angiogenesis, migration, and apoptosis $^{36}$. FGFR3 has been demonstrated to be involved in the RAS/RAF/MEK/MAPK pathway through activation of p90 ribosomal S6 kinase ${ }^{37}$. In addition, it has been reported that FGFRs are frequently overexpressed in
NSCLC cell lines, suggesting that an FGFR-dependent autocrine signaling pathway may operate in a subset of NSCLCs $^{38}$. Based on these observations, it is possible that miR-99b may be involved in lung tumorigenesis through up-regulation of FGFR3.

Albeit a small number of patients were examined, these results suggest that miRNA expression profiles in Korean lung cancers may be somewhat different from the expression profiles reported on lung cancers in Western populations. The findings suggest that miR-99b might be a tumor suppressor through its up-regulation of FGFR3.

\section{References}

1. Ambros V. The functions of animal microRNAs. Nature 
2004; $431: 350-5$.

2. Bartel DP. MicroRNAs: genomics, biogenesis, mechanism, and function. Cell 2004;116:281-97.

3. Lim LP, Lau NC, Garrett-Engele P, Grimson A, Schelter $\mathrm{JM}$, Castle J, et al. Microarray analysis shows that some microRNAs downregulate large numbers of target mRNAs. Nature 2005;433:769-73.

4. Bentwich I, Avniel A, Karov Y, Aharonov R, Gilad S, Barad $\mathrm{O}$, et al. Identification of hundreds of conserved and nonconserved human microRNAs. Nat Genet 2005; 37:766-70.

5. Berezikov E, Guryev V, van de Belt J, Wienholds E, Plasterk RH, Cuppen E. Phylogenetic shadowing and computational identification of human microRNA genes. Cell 2005;120:21-4.

6. Cheng AM, Byrom MW, Shelton J, Ford LP. Antisense inhibition of human miRNAs and indications for an involvement of miRNA in cell growth and apoptosis. Nucleic Acids Res 2005;33:1290-7.

7. Xu P, Guo M, Hay BA. MicroRNAs and the regulation of cell death. Trends Genet 2004;20:617-24.

8. Karp X, Ambros V. Developmental biology. Encountering microRNAs in cell fate signaling. Science 2005;310: 1288-9.

9. Chen CZ, Li L, Lodish HF, Bartel DP. MicroRNAs modulate hematopoietic lineage differentiation. Science 2004; 303:83-6

10. Calin GA, Sevignani C, Dumitru CD, Hyslop T, Noch E, Yendamuri S, et al. Human microRNA genes are frequently located at fragile sites and genomic regions involved in cancers. Proc Natl Acad Sci U S A 2004;101: 2999-3004.

11. Zhang L, Huang J, Yang N, Greshock J, Megraw MS, Giannakakis A, et al. microRNAs exhibit high frequency genomic alterations in human cancer. Proc Natl Acad Sci U S A 2006;103:9136-41.

12. Esquela-Kerscher A, Slack FJ. Oncomirs - microRNAs with a role in cancer. Nat Rev Cancer 2006;6:259-69.

13. Calin GA, Croce CM. MicroRNA signatures in human cancers. Nat Rev Cancer 2006;6:857-66.

14. Gartel AL, Kandel ES. miRNAs: little known mediators of oncogenesis. Semin Cancer Biol 2008;18:103-10.

15. Calin GA, Dumitru CD, Shimizu M, Bichi R, Zupo S, Noch E, et al. Frequent deletions and down-regulation of micro- RNA genes miR15 and miR16 at 13q14 in chronic lymphocytic leukemia. Proc Natl Acad Sci U S A 2002;99:15524-9.

16. Takamizawa J, Konishi H, Yanagisawa K, Tomida S, Osada H, Endoh H, et al. Reduced expression of the let-7 microRNAs in human lung cancers in association with shortened postoperative survival. Cancer Res 2004; 64:3753-6.

17. Johnson SM, Grosshans H, Shingara J, Byrom M, Jarvis $\mathrm{R}$, Cheng A, et al. RAS is regulated by the let-7 microRNA family. Cell 2005;120:635-47.

18. He L, Thomson JM, Hemann MT, Hernando-Monge E, Mu D, Goodson S, et al. A microRNA polycistron as a potential human oncogene. Nature 2005;435:828-33.

19. Hayashita Y, Osada H, Tatematsu Y, Yamada H, Yanagisawa $\mathrm{K}$, Tomida $\mathrm{S}$, et al. A polycistronic microRNA cluster, miR-17-92, is overexpressed in human lung cancers and enhances cell proliferation. Cancer Res 2005;65: 9628-32.

20. Michael MZ, SM OC, van Holst Pellekaan NG, Young GP, James RJ. Reduced accumulation of specific microRNAs in colorectal neoplasia. Mol Cancer Res 2003;1: 882-91.

21. Lu J, Getz G, Miska EA, Alvarez-Saavedra E, Lamb J, Peck D, et al. MicroRNA expression profiles classify human cancers. Nature 2005;435:834-8.

22. Yanaihara N, Caplen N, Bowman E, Seike M, Kumamoto $\mathrm{K}$, Yi M, et al. Unique microRNA molecular profiles in lung cancer diagnosis and prognosis. Cancer Cell 2006;9:189-98

23. Yu SL, Chen HY, Chang GC, Chen CY, Chen HW, Singh S, et al. MicroRNA signature predicts survival and relapse in lung cancer. Cancer Cell 2008;13:48-57.

24. Porkka KP, Pfeiffer MJ, Waltering KK, Vessella RL, Tammela TL, Visakorpi T. MicroRNA expression profiling in prostate cancer. Cancer Res 2007;67:6130-5.

25. Iorio MV, Visone R, Di Leva G, Donati V, Petrocca F, Casalini $\mathrm{P}$, et al. MicroRNA signatures in human ovarian cancer. Cancer Res 2007;67:8699-707.

26. Volinia S, Calin GA, Liu CG, Ambs S, Cimmino A, Petrocca $\mathrm{F}$, et al. A microRNA expression signature of human solid tumors defines cancer gene targets. Proc Natl Acad Sci U S A 2006;103:2257-61.

27. Du YX, Cha Q, Chen XW, Chen YZ, Huang LF, Feng $\mathrm{ZZ}$, et al. An epidemiological study of risk factors for lung cancer in Guangzhou, China. Lung Cancer 1996; 14 Suppl 1:S9-37.

28. Lee C, Kang KH, Koh Y, Chang J, Chung HS, Park SK, et al. Characteristics of lung cancer in Korea, 1997. Lung Cancer 2000;30:15-22.

29. Gazdar AF, Shigematsu H, Herz J, Minna JD. Mutations and addiction to EGFR: the Achilles 'heal' of lung cancers? Trends Mol Med 2004;10:481-6.

30. Marchetti A, Martella C, Felicioni L, Barassi F, Salvatore 
S, Chella A, et al. EGFR mutations in non-small-cell lung cancer: analysis of a large series of cases and development of a rapid and sensitive method for diagnostic screening with potential implications on pharmacologic treatment. J Clin Oncol 2005;23:857-65.

31. John B, Enright AJ, Aravin A, Tuschl T, Sander C, Marks DS. Human MicroRNA targets. PLoS Biol 2004;2:e363.

32. Lewis BP, Shih IH, Jones-Rhoades MW, Bartel DP, Burge CB. Prediction of mammalian microRNA targets. Cell 2003;115:787-98.

33. Krek A, Grun D, Poy MN, Wolf R, Rosenberg L, Epstein EJ, et al. Combinatorial microRNA target predictions. Nat Genet 2005;37:495-500.

34. Lee Y, Jeon K, Lee JT, Kim S, Kim VN. MicroRNA maturation: stepwise processing and subcellular localization. EMBO J 2002;21:4663-70.

35. Wang T, Zhang X, Obijuru L, Laser J, Aris V, Lee P, et al. A micro-RNA signature associated with race, tumor size, and target gene activity in human uterine leiomyomas. Genes Chromosomes Cancer 2007;46:33647.

36. Bernard-Pierrot I, Brams A, Dunois-Larde C, Caillault A, Diez de Medina SG, Cappellen D, et al. Oncogenic properties of the mutated forms of fibroblast growth factor receptor 3b. Carcinogenesis 2006;27:740-7.

37. Kang S, Dong S, Gu TL, Guo A, Cohen MS, Lonial S, et al. FGFR3 activates RSK2 to mediate hematopoietic transformation through tyrosine phosphorylation of RSK2 and activation of the MEK/ERK pathway. Cancer Cell 2007;12:201-14.

38. Marek L, Ware KE, Fritzsche A, Hercule P, Helton WR, Smith JE, et al. Fibroblast growth factor (FGF) and FGF receptor-mediated autocrine signaling in non-small-cell lung cancer cells. Mol Pharmacol 2009;75:196-207. 